\title{
D. PEDRO II EM NOVA ORLEANS $(*)$.
}

\section{ALMIR DE CAMPOS BRUNETI. Tulane University (U.S.A.).}

A medida em que os anos passam, e provavelmente ainda como efeito do nacionalismo inaugurado pelo Movimento Modernista, a ligura de D. Pedro II adquire nuances ambíguas, cujas implicações talvez valesse a pena examinar mais detidamente. Produto do positivismo e impregnado pela cultura da França, que para ele era sa seconde patrie (1), é viavel que a sede de conhecimento e a curiosidade evidenciadas pelo imperador em todos os lugares por onde passou possam ser interpretadas como erudição superficial e cabotinismo. Os críticos literários nunca the perdoaram os maus versos nem se esqueceram das suas pretensões estéticas vis-à-vis de José de Alencar, fato que provavelmente tenderia a validar as palavras de Afonso Celso quando descreve o conceito que os súditos brasileiros tinham do imperadur:

"Inteligência pouco acima do medíocre, ilustração mais extensa que profunda, bonomia filha do ceticismo, magnanimidade oriunda do pouco caso com que considerava os outros homens, tendências absorventes por índole e hábito, gênio de bagatelas como alguem lhe chamou, coração árido, incapaz de devotamentos..." (2).

(*). - Comunicação apresentada na XXVII Reunião Anual da Sociedade Brasileira para o Progresso da Ciência (SBPC) realizada em Belo-Horizonte em julho de 1975. (Nota da Redação).

(1). - Le Lousianais, 20/5/1876, p. 1.

(2). - Afonso Celso, $O$ Imperador no Exílio, nova edição aumentada (Rio de Janei:o. Livraria Francisco Alves, s.d.), p. 4. O livro, entretanto, tem o objetivo de demonstrar que tais impressóes eram errôneas. Ver tambem Raimundo Magalhães Jr., "Anfrísio Fialho e seu republicanismo," in O Império em Chinelos (Rio de Janeiro. Civilização Brasileira, 1957) pp. 233-237. 
Contudo, é incontestavel que D. Pedro II, nas suas viagens ao estrangeiro, e apesar da ogeriza que sentia por quaisquer cerimônias oficiais, tivesse atraido a atenção geral e capitalizado para o Brasil o interesse dos paises visitados. Durante a visita aos Estados Unidos, realizada como preâmbulo de sua segunda viagem à Europa, o imperador causou sensação no país inteiro. Seus passos eram acompanhados pelos leitores dos jornais que se deliciavam com a informalidade, o espírito de humor, e as observações francas do único soberano a visitar o país até aquela data, à exceção do rei Kalakau, do Havaí.

O conhecimento do inglês que possuia o imperador, até mesmo das expressões idiomáticas mais típicas, aliado a um certo espírito galhofeiro, divertia e maravilhava os americanos. O New Orleans Republican, jornal que mais escreveu sobre D. Pedro em Nova Orleans, publica a seguinte nota no dia 20 de maio de 1876 , quatro dias antes da chegada do imperador à cidade. O texto é dado em inglês para não se perder o esforço do cronista em transmitir ao público uma idéia do sotaque do imperador:

"Dom Pedro and the Philadelphia Militia - They used militia to keep order at the grand opening, and as Dom Pedro witnessed their extraordinary maneuvers, he asked in astonishment:

"Vat eez doze?"

"Those are the Philadelphia soldiers, your majesty," eagerly aswered ex-secretary Borie, his face lighting with pride at the fancied compliment to the citizen soldiery.

"Feealdephy soldate, eh?" slowly repeated the monarch, as he gazed at them curiously through his eye-glasses, "and vere eez le General Boum?"

A viagem a Nova Orleans foi realizada depois da abertura oficial da Exposição do Centenário na Filadélfia. Por esta altura, o imperador, que chegara a Nova Iorque no dia 15 de abril, e que surpreendia a todos pelo seu dinamismo e quase ubiquidade, já havia atravessado o país até São Francisco e voltado à costa atlântica, chegando à Filadélfia no dia 9 de maio, véspera das solenidades de abertura da exposição inaugurada no dia 10 conjuntamente por ele e pelo presidente Grant. A viagem inicia-se no dia 14 de maio, quando o imperador parte com destino a St. Louis, onde tomaria um barco para descer o Mississipi. Efetivamente, no dia 18 começa a descida do "pai dos rios" a bordo do vapor Grand Republic, que chega a Nova Orleans no dia 24 pela tarde.

Durante os dias que precederam a chegada do imperador a Nova Orleans, os jornais locais publicavam diariamente notícias sobre o progresso da viagem. Entre essas notícias, as mais interessantes são 
as que dizem respeito à situação econômica do Brasil na época, e que dão ênfase às imensas possibilidades de comércio lucrativo ainda totalmente inexplorado pela cidade que é hoje um dos portos mais importantes na ligação comercial dos Estados Unidos com os portos brasileiros. O New Orleans Bulletin, por exemplo, publica no dia 20 de maio um artigo sob o título "Comércio com o Brasil," em que meticulosamente se analisa o movimento do comércio estadunidense com - Brasil, com resultados extremamente favoráveis ao nosso país. No ano fiscal que terminara a 30 de junho de 1875, os Estados Unidos haviam exportado para o Brasil menos de $1 / 5$ do volume da sua importação. $\mathrm{O}$ articulista termina a sua análise dizendo que para sanar a discrepância, a solução seria estabelecer comunicação direta de Nova Orleans com o Rio de Janeiro. Essa medida viria a diminuir a enorme diferença na balança de comércio especialmente porque traria grandes economias no preço do altíssimo frete que então se pagava para remeter mercadorias ao Brasil via Europa.

Neste mesmo teor, e indiretamente capitalizando sobre as vantagens do comércio direto, o New Orleans Republic do dia 28 de maio traz um artigo intitulado "A riqueza do Brasil," em que, depois de citar a opinião de Agassiz sobre a fertilidade e grandeza do território brasileiro, o articulista exalta as vantagens econômicas de vários produtos, entre os quais cita a castanha, o babaçú, e vários tipos de madeiras. Segundo a descrição, o país era o próprio paraiso. Expressões como

"most productive and interesting country in the globe," ou "the one which it is the easiest to obtain livelihood"

são típicas. O país produzia todas as frutas tropicais quase sem cultivo; o solo em alguns pontos produziria vinte colheitas sucessivas de cana de açucar, algodão, ou fumo, sem necessidade de adubação; as florestas eram virtualmente compostas apenas de madeiras preciosas.

Entretanto, a sugestão mais interessante aparece à página 2 do New Orleans Republican do dia 25 de maio, ainda durante a estada do imperador na cidade, notícia que deve ter sido lida por ele. Os vários jornais da cidade haviam, com efeito, sublinhado a extrema informalidade de $\mathrm{D}$.Pedro. $\mathrm{Na}$ página um do mesmo número do New Orleans Republican havia aparecido um longo artigo noticiando a chegada da comitiva imperial no dia anterior e descrevendo a atividade do imperador nos salões do Hotel St. Charles, onde ele é descrito como

"always pleasant, and having the air of a simple and portly gentleman of the old school." 
Do mesmo modo, o New Orleans Bulletin tambem do dia 25 anuncia em grandes manchetes na página um que

\author{
"Dom Pedro chega - Nenhuma formalidade ou exibição - \\ Ele viaja como o comum dos mortais."
}

Por isso mesmo, o citado artigo da página dois do New Orleans Republican do dia 25, não deve ter passado desapercebido ao imperador. O artigo intitula-se $M r$ D.Pedro, of Rio, e inicia-se com a explicação de que o autor se dirige assim ao ilustre visitante para respeitar a sua vontade de ser considerado como cidadão particular (his styly incognito, como alguem batizara a atitude do soberano na edição do dia 10). Em seguida, acentua mais uma vez as vantagens do estabelecimento de um linha regular direta entre o Rio de Janeiro e Nova Orleans, para então, mais curioso ainda, aconselhar indiretamente o imperador a emancipar os escravos brasileiros, dando como prova insofismavel da praticabilidade de tal medida o fato de que

"the products of emancipated labor are productive of a larger value in market than under the former system of bondage."

Segundo o artigo, se o Brasil seguisse o exemplo dos Estados Unidos, os negros poderiam ter, como lá, seu próprio sistema de igrejas cristãs, jornais, representantes nas profissões liberais, e copiariam incessantemente as instituições de progresso moral e intelectual que distinguiam os Estados Unidos. Alem do mais, poderiam os libertos prestar valioso serviço militar e mesmo ser empregados com vantagem na defesa do país em qualquer emergência. D. Pedro não parece ter se deixado convencer porque numa carta à Condessa do Barral, observa:

“... o Sul da União não é como o Norte apesar da riqueza agrícola dessa região. Veremos o que será em poucos anos sem a escravidão. Os pretos trabalham bem nas fazendas segundo me informaram fazendeiros." (3).

Com relação aos aspectos turísticos da rápida estada do imperador em Nova Orleans, aconteceu o mesmo que em outros lugares. Ele é constantemente seguido pela curiosidade dos Neworleanians e os conquista a todos pelas sua maneiras afáveis e modestas. Os jornais de língua francesa, principalmente, saudaram-no com eloquência

(3). - Alcindo Sodré, Abrindo um Cofre - Cartas de Dom Pedro Il a Condessa do Barral (Rio de Janeiro. Livros de Portugal, 1956), p. 172. 
e dedicaram-lhe longos artigos onde elogiavam barrocamente a sua erudição e sapiência. O Louisianais de 20 de maio traz em letras garrafais um artigo intitulado Vive l'Empereur, onde D. Pedro é comparado com (e pronunciado superior a) o Czar da Rússia, o imperador da Alemanha, e o imperador da Áustria. O exaltado cronista chega a dizer que D. Pedro é superior até mesmo ao General Grant "em tática militar e em literatura." Entre outras coisas, nota que as mulheres brasileiras amam o seu imperador, mas que ele

"n’a point, parât-il, abusé de leur faiblesse."

Observa tambem que, mais do que um imperador, D. Pedro parece ser um fazendeiro, ou melhor, um burguês que vive de rendas.

O número de 26 de maio do Abeille de la Nouvelle Orleans sorri do desapontamento causado entre os que foram ver a chegada do imperador esperando um rei de tragédia com coroa resplandecente na cabeça, cetro na mão, e manto de púrpura nas costas. O patriarca de barbas brancas, modestamente trajado de negro, não correspondia à expectativa da fantasia pública. Mas foi por essa simplicidade austera que o povo se rendeu ao seu hóspede.

O Times Picayune, reportando sobre a visita que D.Pedro fez ao prédio da Alfândega, relata:

"Ās duas horas Dom Pedro chegou à Alfândega. Depois de ter visitado o Departamento dos Correios, ele subiu a longa e tediosa escada com o passo firme de um soldado, e inspecionou o magnífico salão... Durante a p:esença do Imperador na Ilfândega, as opiniões dos mais loquazes entre os espectadores ilustram claramente a impressão que o Dom causa nas massas. Ele trajava o seu costumeiro terno preto e chapéu de feltro. A multidão de curiosos seguiu-o sempre. Um observador entusiasta comentou: "Ora, este é o tipo de rei que eu gosto de ver. Ele vem a um país republicano e veste-se como um republicano. Quando for à Europa colocará a sua coroa." Outra voz: "Quem poderia pensar que este é um imperador? Ele mais parece um capitão de navio." Outros disseram: "Que homem magnífico ele tem o estilo de um imperador. Quão esplêndido deve parecer quando vestido com os signos da sua realeza." Ao parti- o monarca tirou o chapéu com um gesto cortês, e este ato entusiasmou tanto os espectadores que eles estavam dispostos a gritar em uníssono Vive l'Empereur!" 
D. Pedro deixa Nova Orleans com destino a Washington no dia 28 de maio, tendo desenvolvido nesses poucos dias uma atividade realmente surpreendente que incluiu visitas a fábricas, igrejas, escolas, plantações, fazendas, obras contra enchentes, e conferências com médicos, comerciantes, empresários, e outras pessoas gradas, despedindo-se do público oficialmente com uma doação feita ao Clube Dramático da Louisiana. Após breve estadia em Washington, a comitiva segue para - Canadá e termina a viagem em Nova Iorque de onde parte para a Europa no dia 12 de julho de 1876. 